\title{
Relevant Patient Benefit of Sublingual Immunotherapy with Birch Pollen Allergen Extract in Allergic Rhinitis: An Open, Prospective, Non- Interventional Study
}

\author{
Christine Blome - Meike Hadler - Efstrathios Karagiannis • \\ Julia Kisch $\cdot$ Christopher Neht · Nora Kressel • Matthias Augustin
}

Received: February 19, 2020 / Published online: April 28, 2020

(C) The Author(s) 2020

\begin{abstract}
Introduction: Sublingual immunotherapy (SLIT) with birch pollen extract has been shown to be an efficacious treatment of allergic rhinitis (AR). An as-yet unanswered question is whether and how clinical benefit translates into patient benefit, i.e. what benefit patients derive from this treatment.

Methods: This 1-year, open, prospective, multicenter, non-interventional study conducted in 75 German centers measured patient-relevant benefit of birch pollen SLIT (Staloral ${ }^{\circledR}$ Birch) using the questionnaire "Patient Benefit Index for Allergic Rhinitis (PBI-AR)". At treatment onset, patients rated the importance of 25 treatment needs; after the first birch pollen
\end{abstract}

Digital Features To view digital features for this article go to https://doi.org/10.6084/m9.figshare.12091017.

C. Blome $(\bowtie) \cdot J$. Kisch · C. Neht · N. Kressel .

M. Augustin

Institute for Health Services Research in

Dermatology and Nursing (IVDP), University

Medical Center Hamburg-Eppendorf (UKE),

Martinistr. 52, 20246 Hamburg, Germany

e-mail: c.blome@uke.de

M. Hadler

Stallergenes GmbH, Carl-Friedrich-Gauß-Straße 50,

47475 Kamp-Lintfort, Germany

E. Karagiannis

Stallergenes Greer, 6 Rue Alexis de Tocqueville,

92160 Antony, France season on treatment, goal achievement was evaluated. A preference-weighted benefit index was calculated and its association with gender, asthma, allergy status, and severity of AR symptoms was determined.

Results: Mean age of the 291 adult patients was 38.8 years; $58.4 \%$ were female. The most important treatment goals were to "be able to stay outdoors without symptoms" (87.3\% quite or very important), "no longer have a runny or stuffed-up nose" (86.9\%), and "be able to breathe through your nose more freely" $(86.9 \%)$. The treatment goals with the highest benefit ratings (referring to those patients to whom the respective goal applied) were to "have confidence in the therapy" (60.5\% has helped "quite" or "very much"), "have an easily applicable treatment" (55.6\%), and "be able to breathe through my nose more freely" (51.7\%). The average PBI-AR global score was 2.19 (SD 1.04) (0-4; with 4 indicating maximum benefit). No significant differences in PBI-AR global score or subscales were found between men and women, poly- and monoallergic patients, or patients with severe versus mild rhinoconjunctivitis. Patients with asthma reported relevant but lower benefit than patients without asthma. Conclusion: After 1 year of birch pollen SLIT treatment, patients reported considerable benefit, mainly due to a reduction of physical symptoms and treatment burden. 
Keywords: Birch pollen; Patient-relevant benefit; Patient-reported outcomes; Rhinoconjunctivitis; immunotherapy; Treatment goals

\section{Key Summary Points}

Why carry out this study?

Allergic rhinitis has significant impact on patient well-being.

Sublingual immunotherapy with birch pollen extract has proven clinical benefit in allergic rhinitis.

This study evaluates whether and how this clinical benefit translates into patientreported and patient-relevant benefit 1 year after treatment onset.

\section{What was learned from the study?}

Most patients perceived the treatment as at least partially successful in achieving their self-defined treatment goals, in particular with regard to physical symptoms and treatment burden.

\section{INTRODUCTION}

Allergic rhinitis (AR), with or without conjunctivitis, is one of the most common Immunoglobulin E (IgE)-mediated atopic diseases [1]. It is an allergic reaction caused by IgEmediated inflammation of the nasal mucosa which is triggered by a previous sensitization against an allergen. Characteristic symptoms of AR include sneezing, nasal congestion, rhinorrhoea, and nasal pruritus.

$\mathrm{AR}$ is a high-prevalence disease in many developed countries [2-4]. In the European general population, the prevalence of allergic rhinitis was found to be around 25\% [2].

$\mathrm{AR}$ is a disease with "uncontrolled symptoms, impaired quality of life, and unpleasant comorbidities" [5], having a significant impact on patients' well-being [6]. Besides AR symptoms, affected patients can suffer from impaired concentration, sleeping disorders, irritability, decreased performance at school or work, avoidance of outdoor activities, and higher risk for infections. Moreover, $\mathrm{AR}$ is associated with numerous comorbidities, and it is a strong risk factor for the development of allergic asthma: $15-38 \%$ of patients with AR have asthma comorbidity [7].

The management of AR is aimed at controlling symptoms and reducing inflammation. It includes three key pillars: allergen avoidance, targeted pharmacological treatment, and allergen immunotherapy (AIT). Of these, AIT is the only mechanistic-based treatment able to alter the natural course of the disease, with longterm effects after discontinuation of treatment [8]. In addition to improving AR severity, AIT can also successfully prevent the development of associated diseases, such as allergic bronchial asthma [9].

The clinical efficacy of AIT in the treatment of AR and/or asthma has been shown for several standardized AIT products in randomized controlled clinical trials $[8,10]$. However, in addition to clinical efficacy, it is pivotal to determine the benefit of a treatment in real-life clinical practice from the patients' perspective, i.e. to determine whether clinical benefit translates into patient benefit. Perceived benefit is crucial, not only as a pivotal endpoint in itself but also because it can be expected to increase treatment satisfaction and adherence to treatment, and can subsequently help to improve treatment efficacy. Benefit will depend on the patients' treatment goals and expectations, which in turn are determined by their individual life style, circumstances, and preferences. Patients' expectations often go beyond measurable symptom reductions [11]. Besides a relief of symptoms, patients generally expect a reduction of morbidity, improvement in quality of life, and a reduction of treatment burden (defined as the workload of healthcare for the patients and its impact on patient functioning and well-being [12]). The benefit that a treatment has in patients' lives can only be evaluated by the patients themselves, not by the treating clinicians. 
Focussing on birch pollen allergy, a major source of AR in Europe [13], the aim of this reallife medical practice study was to determine the patient-relevant benefit of a birch pollen sublingual immunotherapy (SLIT) treatment from the AR patients' perspective by using the Patient Benefit Index Allergic Rhinitis (PBI-AR). The efficacy of this birch pollen SLIT treatment had been shown previously in two double-blind, placebo-controlled randomized clinical trials $[14,15]$.

The PBI-AR is a standardized and validated instrument which has been shown to be correlated with treatment satisfaction, patient health-related quality of life, and treatment burden, with more satisfied and less burdened patients showing higher patient benefit [11].

The PBI-AR global benefit score was the primary outcome of this study. In further analyses, we aimed to determine the distribution of treatment goals, goal achievement, and PBI-AR subscale scores, and to determine associations of the PBI-AR with a number of patient characteristics as well as global benefit ratings by patients and physicians.

\section{METHODS}

\section{Study Design}

This was a 1-year, open, prospective, multicenter, non-interventional study in patients treated with birch pollen SLIT. The study protocol was approved by the Freiburg Ethics Commission International. Patients gave written informed consent and the study conformed with the Helsinki Declaration of 1964, as revised in 2013, concerning human rights.

\section{Procedures}

Patients were recruited between autumn 2012 and the first quarter of 2013 by 75 allergologically experienced specialists (mainly ear, nose, and throat physicians, dermatologists, and pulmonologists) working in secondary care across Germany. Each investigator was asked to recruit three or more consecutive patients for whom the decision to initiate birch pollen SLIT had already been taken. The nationwide recruitment of investigators and consecutive enrolment of eligible patients should ensure that a representative sample from the patient population was selected. Patients were included in the study after the decision for birch pollen SLIT had already been made.

Eligible for this study were male or female patients ( $\geq 18$ years) presenting with birch pollen-induced allergic rhinitis, conjunctivitis, rhinoconjunctivitis, and/or mild asthma confirmed by a positive skin prick test and/or a positive serum titre of specific IgE, and who gave their written informed consent. Exclusion criteria were: hypersensitivity to any of the excipients of the sublingual solution; immune deficiency or autoimmune diseases; malignant diseases; uncontrolled or severe asthma [forced expiratory volume in $1 \mathrm{~s}\left(\mathrm{FEV}_{1}\right)<70 \%$ of predicted value]; or inflammatory conditions in the oral cavity.

Two visits were planned during the observation phase: a study initiation visit at the beginning of treatment and a study end visit after the first birch pollen season with SLIT (birch pollen season 2013). During each visit, investigators completed an electronic case report form (eCRF) for each patient, while patients filled in a paper-based questionnaire. At the first visit, investigators documented baseline data, such as demographic data, medical history (clinical manifestations of the allergy. i.e. rhinitis, conjunctivitis, asthma, atopic dermatitis; concomitant allergies), concomitant diseases and medication, impairment due to allergic symptoms in the tree pollen season before birch pollen SLIT treatment start [Allergic Rhinitis Impact on Asthma (ARIA) classification of allergic rhinitis symptoms, severity of symptoms], and start date of SLIT. Patients assessed their patient needs, i.e. their treatment-related expectations. At the second visit, documentation included data on treatment, impairment due to allergic symptoms during the first tree pollen season on SLIT treatment, and treatment-related patient benefit. Physicians' and patients' judgements on improvement in well-being were also assessed at the second visit. 
In this article, we report the main outcomes of the study, i.e. patient needs/expectations and benefits as measured with the Patient Benefit Index (PBI).

\section{Study Treatment}

Patients were treated with Staloral ${ }^{\circledR}$ Birch 300 IR/ml (Stallergenes, Antony, France), a sublingual solution of standardized birch pollen allergen extract at a concentration of $10 \mathrm{IR} / \mathrm{ml}$ (during the titration phase) and $300 \mathrm{IR} / \mathrm{ml}$ (during both the titration and maintenance phases). IR (= index of reactivity) is an in-house unit to express biological activity. Treatment was initiated with an 11-day titration phase with increasing doses of the $10 \mathrm{IR} / \mathrm{ml}(1,2,4,6$, 8 , and 10 puffs) and the $300 \mathrm{IR} / \mathrm{ml}$ concentration $(1,2,4,6$, and 8 puffs), followed by a maintenance phase. According to the investigators' prescriptions, patients took 4 or 8 puffs of the $300 \mathrm{IR} / \mathrm{ml}$ concentration once daily during the maintenance phase, following either a perennial or a pre-/co-seasonal treatment schedule. The extract had to be placed directly under the tongue and kept there for $2 \mathrm{~min}$ before being swallowed.

\section{The Patient Benefit Index}

The PBI is a standardized and validated instrument that measures patient-reported treatment needs and benefits; there are both a standard version for dermatological indications [16] and an indication-specific version. Each PBI version consists of 2 questionnaires: The Patient Needs Questionnaire (PNQ) is filled in before treatment. It consists of standardized items on predefined treatment goals that refer to symptom reduction (e.g. "no longer have a runny or stuffed up nose"; "not have sneezing impulses anymore"), but also to improvement of quality of life (e.g. "be able to engage in normal leisure activities") and low burden of the treatment itself (e.g. "have fewer side effects"). Patients rate the importance of each goal on a Likert scale ranging from $0=$ "not at all [important]" to $4=$ "very [important]". The Patient Benefit Questionnaire (PBQ) is filled in during or after therapy. It consists of the same items as the PNQ, but the instructions differ. Here, the patients rate the extent to which the treatment needs have been achieved by therapy using a Likert scale ranging from $0=$ "not at all" to $4=$ "very". As an alternative, the patient can tick "does not apply to me" in the PNQ and "did not apply to me" in the PBQ; in that case, the item is considered irrelevant for further procedures. A weighted index value, the actual PBI, is calculated by multiplying the achieved benefits (PBQ) with the importance of the respective needs prior to therapy (PNQ), dividing these products by the sum of all importance items and summing them up for all items. The PBI ranges from 0 (no benefit) to 4 (maximal benefit). A PBI score $>1$ is considered relevant; this cut-off was based on correlations with convergent criteria (unpublished data).

In this study, the PBI version for patients with allergic rhinitis (PBI-AR) was used. It includes items on needs and benefits that are specifically relevant for this patient group. The PBI-AR has been validated in adult patients with allergic rhinitis [11]. For the PBI-AR, both a global score on overall benefit and subscales scores on different dimensions of benefit (psychological burden, treatment burden, physical symptoms, activity/physical capability) can be computed.

\section{Statistical Analysis}

In addition to descriptive analyses (frequency, mean, standard deviation, median, interquartile range, range), associations of $\mathrm{PBI}-\mathrm{AR}$ global score and subscale scores with patient characteristics were determined.

We used the $t$-test for independent samples for binary characteristics: gender; poly- versus monoallergic patients; patients with versus without asthma; mild versus severe rhinoconjunctivitis; intermittent versus persistent allergic rhinitis, according to the ARIA classification [17]; decrease in rhinitis symptom, yes versus no; decrease in conjunctivitis symptoms, yes versus no. For the latter two variables, patients were classified into the two groups based on the physicians' judgement on symptoms at first and 
second visit with the response options "none", "mild", "moderate", and "severe"; patients without symptoms at first visit were excluded from this analysis.

Analyses of variance were used for comparisons between three groups (improvement in well-being as rated by physicians and patients, respectively: "much better", "somewhat better", or "unchanged"). For these analyses, the subgroups with the response "worse" had to be excluded for being too small for inclusion in the statistical analysis (physicians: $n=4$; patients: $n=8$ )

This was a per-protocol analysis; no missing data were imputed. Data were analyzed using SPSS v.22 (IBM, Armonk, NY, USA).

\section{RESULTS}

\section{General Epidemiological Data}

Data were available for 346 participants. Of these, 20 were excluded from the overall analysis due to age $<18$ years $(n=7)$, retrospective documentation $(n=10)$, or failure to take the birch pollen SLIT $(n=3)$. Another 35 patients were excluded from the PBI analysis because they completed the PBI at the wrong time point, namely: (1) the PNQ was completed later than 21 days after treatment onset (at this time, treatment effects may already be present, which may influence the needs rating), (2) the PNQ was completed after the start of the birch pollen season, (3) the PBQ was completed before the birch pollen season, or (4) the PBQ was completed before treatment onset.

Of 291 patients included in the PBI analysis, 42 had completed neither the PNQ nor the PBQ. Thus, 249 patients with partial or complete PBI data remained. Of these, 4 had not completed the PNQ, and 33 had not completed the PBQ; for the remaining 212 patients, PBI global scores could be calculated.

Mean age of the 291 patients was 38.8 [standard deviation $(\mathrm{SD})=13.0$ ] years with a range of 18-78 years (Table 1), 58.4\% were female, and $74.2 \%$ were diagnosed with allergic conjunctivitis in addition to allergic rhinitis (the latter present in 98.6\%; Table 1). Birch
Table 1 Patient characteristics at first visit $(n=291)$

\begin{tabular}{ll}
\hline Characteristics & $n$ (\% of 291) \\
\hline Gender & $121(41.6)$ \\
Male & $170(58.4)$ \\
Female & \\
Symptoms & $287(98.6)$ \\
Allergic rhinitis & $94(32.5)$ \\
Intermittent ${ }^{\mathrm{a}}$ & $195(67.5)$ \\
Persistent & \\
Allergic conjunctivitis & $216(74.2)$ \\
Severity of rhinoconjunctivitis symptoms & \\
Mild & $59(20.3)$ \\
Severe & $232(79.7)$ \\
Asthma & $66(22.7)$ \\
Tree pollen allergy to & \\
Birch & $290(99.7)$ \\
Alder & $222(76.3)$ \\
Hazel & $212(72.9)$ \\
Concomitant allergies (other than tree pollen) \\
No (= monoallergic patient) & $127(43.6)$ \\
Yes (= polyallergic patient) & $164(56.4)$ \\
Age & \\
Mean (SD) [years] & $38.8(13.0)$ \\
Range [years] & $18-78$ \\
\hline
\end{tabular}

${ }^{a}$ According to ARIA classification [17]: Intermittent $A R$ symptoms occurring $<4$ days a week $\mathrm{OR}<4$ consecutive weeks; Persistent $A R$ symptoms occurring $>4$ days a week AND $>4$ consecutive weeks

b Severe rhinoconjunctivitis was assumed if the sum of the severity assessments for rhinitis and conjunctivitis symptoms was $\geq 4$, with the following response options for each of the two variables (physician global ratings): $0=$ none, $1=$ mild, $2=$ moderate, $3=$ severe

pollen allergy was most prevalent (99.7\%; Table 1). 
Table 2 Patient-rated importance of goals in birch pollen sublingual immunotherapy (SLIT) treatment, as measured with the Patient Needs Questionnaire (PNQ) within the PBI-AR (first visit; $n=245$ patients who completed the PNQ at least partially)

\begin{tabular}{|c|c|c|c|c|c|}
\hline \multirow{2}{*}{$\begin{array}{l}\text { Item (treatment goal) } \\
\text { As a result of therapy, how } \\
\text { important is it for you to... }\end{array}$} & \multirow[t]{2}{*}{$n$} & \multirow{2}{*}{$\begin{array}{l}\text { Importance } \\
\text { rating } \\
\text { mean }(S D)^{a}\end{array}$} & \multirow{2}{*}{$\begin{array}{l}\text { Does apply: } \\
n(\% \text { of } n=245)\end{array}$} & \multicolumn{2}{|c|}{ Importance rating: $n(\%$ of $n=245)$} \\
\hline & & & & $\begin{array}{l}\text { Not at all/somewhat/ } \\
\text { moderately/ } \\
\text { does not apply }\end{array}$ & $\begin{array}{l}\text { Quite/ } \\
\text { very }\end{array}$ \\
\hline $\begin{array}{l}\text { 1. ... Not have sneezing impulses } \\
\text { anymore }(\mathrm{S} 3)\end{array}$ & 245 & $3.26(0.99)$ & $243(99.2)$ & $51(20.8)$ & $194(79.2)$ \\
\hline $\begin{array}{l}\text { 2. ... No longer have a runny or } \\
\text { stuffed up nose (S3) }\end{array}$ & 245 & $3.51(0.83)$ & $244(99.6)$ & $32(13.1)$ & $213(86.9)$ \\
\hline $\begin{array}{l}\text { 3. ... Be able to breathe through your } \\
\text { nose more freely }(\mathrm{S} 3)\end{array}$ & 244 & $3.45(0.92)$ & $241(98.4)$ & $32(13.1)$ & $213(86.9)$ \\
\hline 4.... Feel less fatigued or groggy (S4) & 245 & $2.93(1.25)$ & $227(92.7)$ & $74(30.2)$ & $171(69.8)$ \\
\hline $\begin{array}{l}5 \ldots . . \text { Be able to stay outdoors without } \\
\text { symptoms (S3) }\end{array}$ & 244 & $3.44(0.88)$ & $241(98.4)$ & $31(12.7)$ & $214(87.3)$ \\
\hline 6.... Feel less irritated $(\mathrm{S} 1)$ & 245 & $2.32(1.49)$ & $213(86.9)$ & $121(49.4)$ & $124(50.6)$ \\
\hline $\begin{array}{l}7 \ldots . \text { Have an easily applicable } \\
\text { treatment }(\mathrm{S} 2)\end{array}$ & 244 & $2.87(1.30)$ & $224(91.4)$ & $81(33.2)$ & $164(66.8)$ \\
\hline $\begin{array}{l}8 \ldots . . \text { Not have itching on the eyes, } \\
\text { nose or palate anymore }(\mathrm{S} 3)\end{array}$ & 245 & $3.17(1.26)$ & $232(94.7)$ & $53(21.6)$ & $192(78.4)$ \\
\hline $\begin{array}{l}9 . . . \text { Not have burning or watery eyes } \\
\text { anymore }(\mathrm{S} 3)\end{array}$ & 245 & $3.17(1.24)$ & $232(94.7)$ & $54(22.0)$ & $191(78.0)$ \\
\hline $10 \ldots$. Be healed of all symptoms (S3) & 245 & $3.16(1.25)$ & $227(92.7)$ & $50(20.4)$ & $195(79.6)$ \\
\hline $11 \ldots$. Be able to sleep better $(S 1)$ & 245 & $2.75(1.45)$ & $213(86.9)$ & $83(34.0)$ & $162(66.0)$ \\
\hline $12 \ldots$. Feel less depressed $(\mathrm{S} 1)$ & 245 & $2.31(1.50)$ & $206(84.1)$ & $122(49.8)$ & $123(50.2)$ \\
\hline $\begin{array}{l}13 . . . \text { Experience a greater enjoyment } \\
\text { of life }(S 1)\end{array}$ & 245 & $2.32(1.54)$ & $201(82.0)$ & $120(49.0)$ & $125(51.0)$ \\
\hline $\begin{array}{l}14 \ldots . \text { Have no fear that the disease } \\
\text { will become worse }(\mathrm{S} 1)\end{array}$ & 245 & $2.54(1.49)$ & $212(86.5)$ & $103(42.0)$ & $142(58.0)$ \\
\hline $\begin{array}{l}15 \ldots . . \text { Be more productive in everyday } \\
\text { life }(\mathrm{S} 4)\end{array}$ & 245 & $2.99(1.21)$ & $232(94.7)$ & $68(27.8)$ & $177(72.2)$ \\
\hline $\begin{array}{l}16 \ldots . . \text { Be able to engage in normal } \\
\text { leisure activities }(\mathrm{S} 4)\end{array}$ & 244 & $3.20(1.05)$ & $238(97.1)$ & $48(19.7)$ & $197(80.3)$ \\
\hline $\begin{array}{r}17 \ldots . \text { Be comfortable showing } \\
\text { yourself more in public }(S 1)\end{array}$ & 242 & $1.93(1.54)$ & $192(78.5)$ & $147(59.9)$ & $98(40.1)$ \\
\hline $\begin{array}{l}18 \ldots . . \text { Be able to concentrate better at } \\
\text { work (S4) }\end{array}$ & 245 & $2.62(1.48)$ & $211(86.1)$ & $93(38.0)$ & $152(62.0)$ \\
\hline
\end{tabular}


Table 2 continued

\begin{tabular}{|c|c|c|c|c|c|}
\hline \multirow{2}{*}{$\begin{array}{l}\text { Item (treatment goal) } \\
\text { As a result of therapy, how } \\
\text { important is it for you to... }\end{array}$} & \multirow[t]{2}{*}{$n$} & \multirow{2}{*}{$\begin{array}{l}\text { Importance } \\
\text { rating } \\
\text { mean }(\mathrm{SD})^{\mathrm{a}}\end{array}$} & \multirow{2}{*}{$\begin{array}{l}\text { Does apply: } \\
n(\% \text { of } n=245)\end{array}$} & \multicolumn{2}{|c|}{ Importance rating: $n(\%$ of $n=245)$} \\
\hline & & & & $\begin{array}{l}\text { Not at all/somewhat/ } \\
\text { moderately/ } \\
\text { does not apply }\end{array}$ & $\begin{array}{l}\text { Quite/ } \\
\text { very }\end{array}$ \\
\hline $\begin{array}{l}19 . . . \text { Be less burdened in your } \\
\text { partnership }(S 1)\end{array}$ & 244 & $1.92(1.57)$ & $183(74.6)$ & $143(58.2)$ & $102(41.8)$ \\
\hline $\begin{array}{l}20 \ldots . \text { Be able to have a normal sex } \\
\text { life }(S 1)\end{array}$ & 241 & $1.65(1.62)$ & $174(71.0)$ & $161(65.6)$ & $84(34.4)$ \\
\hline $\begin{array}{l}21 \ldots . \text { Be less dependent on doctor } \\
\text { and clinic visits (S2) }\end{array}$ & 244 & $2.47(1.44)$ & $213(86.9)$ & $112(45.9)$ & $133(54.1)$ \\
\hline $\begin{array}{l}22 \ldots . . \text { Need less time for daily } \\
\text { treatment }(\mathrm{S} 2)\end{array}$ & 243 & $2.57(1.40)$ & $218(88.9)$ & $104(42.4)$ & $141(57.6)$ \\
\hline $\begin{array}{l}23 . . . \text { Have fewer out-of-pocket } \\
\text { treatment expenses (S2) }\end{array}$ & 245 & $2.51(1.45)$ & $226(92.2)$ & $113(46.1)$ & $132(53.9)$ \\
\hline $24 \ldots$. Have fewer side effects (S2) & 245 & $2.65(1.50)$ & $216(88.2)$ & $100(40.8)$ & $145(59.2)$ \\
\hline $\begin{array}{l}25 . . . \text { Have confidence in the therapy } \\
\text { (S2) }\end{array}$ & 245 & $3.03(1.32)$ & $222(90.6)$ & $68(27.8)$ & $177(72.2)$ \\
\hline
\end{tabular}

$S 1$ item from subscale "psychological burden", $S 2$ item from subscale "treatment burden", $S 3$ item from subscale "physical symptoms", $S 4$ item from subscale "activity/physical capability"

${ }^{\text {a }}$ Range $0=$ no importance to $4=$ highest importance

\section{Patient-Relevant Needs}

Patient needs/expectations are shown in Table 2. The most important treatment goals were to "be able to stay outdoors without symptoms" ("quite" or "very" important to $87.3 \%$ of patients), "no longer have a runny or stuffed up nose" (86.9\%), "be able to breathe through your nose more freely" (86.9\%), and "be able to engage in normal leisure activities" $(80.3 \%)$. The lowest importance was found for the goal to "be able to have a normal sex life" (34.4\%). Generally, expectations related to the reduction of physical symptoms received the highest mean ratings from the patients, i.e. were considered most important.

\section{Patient-Relevant Benefit}

Patient assessments of benefits provided by birch pollen SLIT are detailed in Table 3. The treatment goals with the highest benefit ratings (referring to those patients to whom the respective goal applied) were to "have confidence in the therapy" (has helped "quite" or "very much" in $60.5 \%$ of patients), "have an easily applicable treatment" (55.6\%), "be able to breathe through my nose more freely" (51.7\%), and "not have sneezing impulses anymore" $(51.2 \%)$. The lowest benefit ratings were given for "be less burdened in your partnership" with $29.8 \%$ and "be able to have a normal sex life" with $30.7 \%$.

\section{Patient Benefit Index Global and Subscale Scores}

The average weighted PBI-AR global score on overall treatment benefit of the birch pollen SLIT was 2.19 (SD 1.04; Fig. 1; Table 4; possible range $0-4$ with 4 indicating maximum benefit). A total of $81.1 \%$ patients $(n=172)$ attained an at least minimally relevant benefit of 1.0 or higher. For the subscale "treatment burden", the 
Table 3 Patient-rated achievement of treatment goals due to the birch pollen sublingual immunotherapy (SLIT) treatment, as measured with the Patient Benefit Questionnaire (PBQ) within the PBI-AR (second visit; $n=216$ patients who completed the PBQ at least partially)

\begin{tabular}{|c|c|c|c|c|c|}
\hline \multirow{2}{*}{$\begin{array}{l}\text { Item (treatment benefit) } \\
\text { The current treatment } \\
\text { has helped me to... }\end{array}$} & \multirow{2}{*}{$\begin{array}{l}n \text { (number of } \\
\text { patients who } \\
\text { answered this } \\
\text { item and did } \\
\text { not choose "did } \\
\text { not apply") }\end{array}$} & \multirow{2}{*}{$\begin{array}{l}\text { Benefit } \\
\text { rating: } \\
\text { mean } \\
(\mathrm{SD})^{\mathrm{a}}\end{array}$} & \multirow[t]{2}{*}{$\begin{array}{l}\text { Does apply: } n(\% \\
\text { of } n=216)\end{array}$} & \multicolumn{2}{|c|}{$\begin{array}{l}\text { Benefit rating: } n \text { (\% of } \\
n=216 \text { ) }\end{array}$} \\
\hline & & & & $\begin{array}{l}\text { Not at } \\
\text { all/somewhat/ } \\
\text { moderately }\end{array}$ & $\begin{array}{l}\text { Quite/ } \\
\text { very }\end{array}$ \\
\hline $\begin{array}{l}\text { 1. ... Not have sneezing impulses } \\
\text { anymore }(\mathrm{S} 3)\end{array}$ & 215 & $2.26(1.18)$ & $216(100.0)$ & $105(48.8)$ & $111(51.2)$ \\
\hline $\begin{array}{l}\text { 2. ... No longer have a runny or } \\
\text { stuffed up nose }(\mathrm{S} 3)\end{array}$ & 214 & $2.22(1.20)$ & $214(99.1)$ & $110(50.9)$ & $106(49.1)$ \\
\hline $\begin{array}{l}\text { 3. ... Be able to breathe through my } \\
\text { nose more freely }(\mathrm{S} 3)\end{array}$ & 211 & $2.32(1.18)$ & $213(98.6)$ & $104(48.3)$ & $112(51.7)$ \\
\hline 4. ... Feel less fatigued or groggy (S4) & 205 & $2.15(1.23)$ & $205(94.9)$ & $121(56.1)$ & $95(43.9)$ \\
\hline $\begin{array}{l}5 . \ldots \text { Be able to stay outdoors without } \\
\text { symptoms (S3) }\end{array}$ & 211 & $2.12(1.29)$ & $212(98.1)$ & $122(56.4)$ & $94(43.6)$ \\
\hline 6. ... Feel less irritated $(S 1)$ & 183 & $1.85(13.0)$ & $185(85.5)$ & $138(63.9)$ & $78(36.1)$ \\
\hline $\begin{array}{l}\text { 7. ... Have an easily applicable } \\
\text { treatment (S2) }\end{array}$ & 207 & $2.48(1.27)$ & $208(96.3)$ & $96(44.4)$ & $120(55.6)$ \\
\hline $\begin{array}{l}\text { 8. ... Not have itching on the eyes, } \\
\text { nose or palate anymore }(S 3)\end{array}$ & 205 & $2.24(1.24)$ & $205(94.9)$ & $112(51.7)$ & $104(48.3)$ \\
\hline $\begin{array}{l}\text { 9. ... Not have burning or watery eyes } \\
\text { anymore }(\mathrm{S} 3)\end{array}$ & 205 & $2.25(1.28)$ & $206(95.3)$ & $106(49.3)$ & $110(50.7)$ \\
\hline 10. ... Be healed of all symptoms (S3) & 204 & $1.93(1.35)$ & $204(94.4)$ & $137(63.2)$ & $79(36.8)$ \\
\hline 11. ... Be able to sleep better (S1) & 197 & $2.15(1.28)$ & $198(91.6)$ & $123(56.9)$ & $93(43.1)$ \\
\hline 12. ... Feel less depressed (S1) & 181 & $1.93(1.26)$ & $181(83.8)$ & $132(61.3)$ & $84(38.7)$ \\
\hline $\begin{array}{l}\text { 13. ... Experience a greater enjoyment } \\
\text { of life (S1) }\end{array}$ & 184 & $1.94(1.25)$ & $184(85.2)$ & $137(63.6)$ & $79(36.4)$ \\
\hline $\begin{array}{l}\text { 14. ... Have no fear that the disease } \\
\text { will become worse }(S 1)\end{array}$ & 184 & $2.08(1.34)$ & $184(85.2)$ & $115(53.3)$ & $101(46.7)$ \\
\hline $\begin{array}{l}15 . . . \text { Be more productive in everyday } \\
\text { life }(S 4)\end{array}$ & 207 & $2.13(1.26)$ & 207 (95.8) & $119(55.1)$ & $97(44.9)$ \\
\hline $\begin{array}{l}\text { 16. ... Be able to engage in normal } \\
\text { leisure activities }(S 4)\end{array}$ & 209 & $2.15(1.21)$ & $209(96.8)$ & $120(55.5)$ & $96(44.5)$ \\
\hline $\begin{array}{l}\text { 17. ... Be comfortable showing myself } \\
\text { more in public }(S 1)\end{array}$ & 171 & $1.85(1.25)$ & $174(80.7)$ & $145(67.3)$ & $71(32.7)$ \\
\hline
\end{tabular}


Table 3 continued

\begin{tabular}{|c|c|c|c|c|c|}
\hline \multirow{2}{*}{$\begin{array}{l}\text { Item (treatment benefit) } \\
\text { The current treatment } \\
\text { has helped me to... }\end{array}$} & \multirow{2}{*}{$\begin{array}{l}n \text { (number of } \\
\text { patients who } \\
\text { answered this } \\
\text { item and did } \\
\text { not choose "did } \\
\text { not apply") }\end{array}$} & \multirow{2}{*}{$\begin{array}{l}\text { Benefit } \\
\text { rating: } \\
\text { mean } \\
(\mathrm{SD})^{\mathrm{a}}\end{array}$} & \multirow[t]{2}{*}{$\begin{array}{l}\text { Does apply: } n(\% \\
\text { of } n=216)\end{array}$} & \multicolumn{2}{|c|}{$\begin{array}{l}\text { Benefit rating: } n \text { (\% of } \\
n=216)\end{array}$} \\
\hline & & & & $\begin{array}{l}\text { Not at } \\
\text { all/somewhat/ } \\
\text { moderately }\end{array}$ & $\begin{array}{l}\text { Quite/ } \\
\text { very }\end{array}$ \\
\hline $\begin{array}{l}\text { 18. ... Be able to concentrate better } \\
\text { at work }(\mathrm{S} 4)\end{array}$ & 194 & $2.07(1.22)$ & $195(90.2)$ & $125(57.7)$ & $91(42.3)$ \\
\hline $\begin{array}{l}\text { 19. ... Be less burdened in your } \\
\text { partnership (S1) }\end{array}$ & 161 & $1.75(1.25)$ & $163(75.6)$ & $152(70.2)$ & $64(29.8)$ \\
\hline $\begin{array}{l}\text { 20. ... Be able to have a normal sex } \\
\text { life }(S 1)\end{array}$ & 153 & $1.69(1.32)$ & $157(72.9)$ & $150(69.3)$ & $66(30.7)$ \\
\hline $\begin{array}{l}\text { 21. ... Be less dependent on doctor } \\
\text { and clinic visits }(\mathrm{S} 2)\end{array}$ & 186 & $1.96(1.30)$ & $187(86.5)$ & $130(60.2)$ & $86(39.8)$ \\
\hline $\begin{array}{l}\text { 22. ... Need less time for daily } \\
\text { treatment (S2) }\end{array}$ & 198 & $2.23(1.29)$ & $199(92.1)$ & $110(51.0)$ & $106(49.0)$ \\
\hline $\begin{array}{l}\text { 23. ... Have fewer out-of-pocket } \\
\text { treatment expenses (S2) }\end{array}$ & 203 & $2.16(1.35)$ & $205(94.9)$ & $120(55.7)$ & $96(44.3)$ \\
\hline 24. ... Have fewer side effects (S2) & 196 & $2.31(1.29)$ & $199(92.0)$ & $109(50.5)$ & $107(49.5)$ \\
\hline $\begin{array}{l}\text { 25. ... Have confidence in the } \\
\text { therapy (S2) }\end{array}$ & 200 & $2.55(1.32)$ & $201(93.0)$ & $85(39.5)$ & $131(60.5)$ \\
\hline
\end{tabular}

$S 1$ item from subscale "psychological burden", $S 2$ item from subscale "treatment burden", $S 3$ item from subscale "physical symptoms", $S 4$ item from subscale "activity/physical capability"

${ }^{\text {a }}$ Range $0=$ no benefit to $4=$ highest benefit)

highest PBI-AR score was achieved with 2.26, followed by "physical symptoms" with 2.15; for "psychological burden", the benefit was lowest with 1.83 (Table 4).

\section{Association of Treatment Benefit with Other Outcomes}

The PBI-AR global score was positively associated with an improvement in well-being as rated by physicians and patients (Fig. 2). As stated above, the subgroup with the response "worse" had to be excluded due to small sample sizes (physicians: $n=4$; patients: $n=8$ ). The differences between the three groups ("much better", "somewhat better", and "unchanged") were highly significant for both physicians' and patients' judgement $(p<0.001)$.

Furthermore, the PBI-AR global score was positively associated with the decrease in rhinitis symptoms as rated by the physicians. Patients whose rhinitis symptoms had improved in the birch pollen season with SLIT treatment compared to the previous birch pollen season without treatment had a significantly higher PBI-AR score (mean PBI$\mathrm{AR}=2.31, \mathrm{SD}=1.03, n=165$ ) than patients whose rhinitis symptoms had not decreased (mean PBI-AR $=1.70, \quad \mathrm{SD}=0.92, n=44$ ) $(p<0.001)$.

For conjunctivitis symptoms, however, the PBI-AR in patients whose symptoms according to the physicians' judgement had decreased 


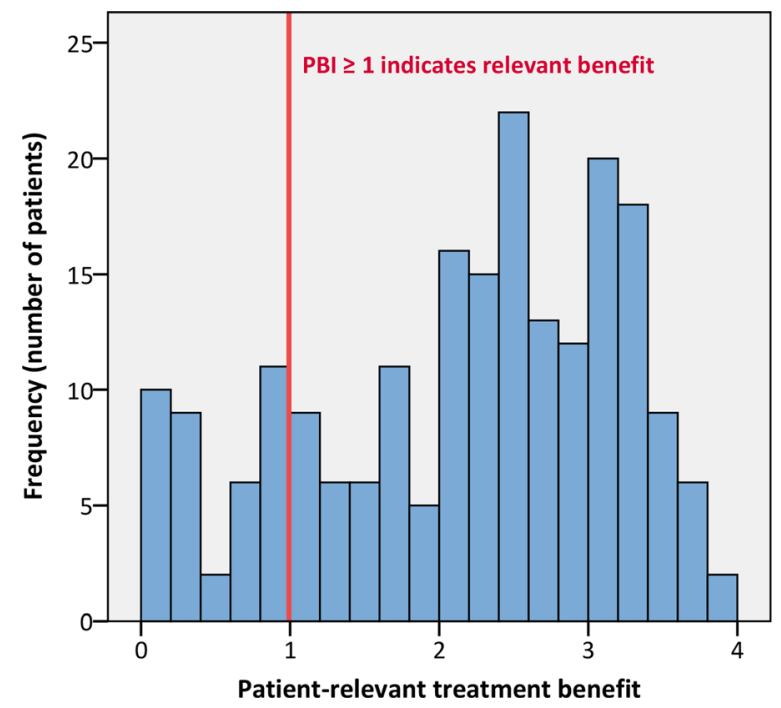

Fig. 1 Distribution of patient-relevant benefit from sublingual immunotherapy (SLIT): PBI-AR global score, ranged $0=$ no benefit to $4=$ maximum benefit

(mean PBI-AR $=2.24$, SD 1.06, $n=144$ ) was not significantly higher than in patients whose symptoms had not decreased (mean PBI-AR = 2.03, SD 0.84, $n=45)(p=0.173)$.

\section{Subgroup Analyses}

The patient-relevant outcomes of birch pollen SLIT as measured by the PBI-AR (Table 5) and its subscales (data not shown) were not significantly different regarding gender, concomitant allergies (poly- vs. monoallergic patients), or severity of rhinoconjunctivitis. Patients with asthma showed lower treatment benefit than patients without asthma in both PBI-AR global scores and subscale scores. However, average benefit in patients with asthma was well above the cut-off value for minimal relevant benefit $(\geq 1)$. Patients with intermittent allergic rhinitis had higher PBI-AR scores in the subscale on "physical symptoms" than those with persistent allergic rhinitis, but no significant differences were found in the PBI-AR global score and in the remaining subscales.

\section{DISCUSSION}

The aim of this study was to evaluate the incremental therapeutic patient benefit from SLIT with birch pollen extract in patients with birch pollen-related allergic rhinoconjunctivitis. In order to identify a broad spectrum of patient-relevant needs and outcomes, the PBI was used. Previous studies have demonstrated its validity and feasibility in a variety of conditions, including allergic rhinitis [11].

At baseline, patients with birch pollen induced $A R$ had specific and multi-faceted treatment needs, particularly related to relief from physical symptoms of rhinitis, as well as regarding the ability to have normal leisure activities and to be outdoors. Treatment goals of patients with AR reported in previous publications include symptom reduction, better sleep, being able to undertake normal daily activities, and not having side effects $[17,18]$, all of which could be confirmed by the results of the present study.

Table 4 Distribution of PBI-AR scores and subdimensions on patient-relevant benefit from birch pollen sublingual immunotherapy (SLIT) treatment

\begin{tabular}{lllll}
\hline & $n$ & Mean (SD) & Median (IQR) & Minimum-maximum \\
\hline PBI-AR global score & 212 & $2.19(1.04)$ & $2.38(1.37-3.01)$ & $0.00-4.00$ \\
PBI-AR subscale 1: "psychological burden" & 192 & $1.83(1.12)$ & $1.88(1.00-2.64)$ & $0.00-4.00$ \\
PBI-AR subscale 2: "treatment burden” & 202 & $2.26(0.40)$ & $2.41(1.48-3.17)$ & $0.00-4.00$ \\
PBI-AR subscale 3: "physical symptoms" & 211 & $2.15(1.08)$ & $2.43(1.19-3.00)$ & $0.00-4.00$ \\
PBI-AR subscale 4: "activity/physical capability" & 209 & $2.06(1.14)$ & $2.17(1.05-3.00)$ & $0.00-4.00$ \\
\hline
\end{tabular}

PBI-AR scores range from $0=$ no benefit to $4=$ maximum benefit 


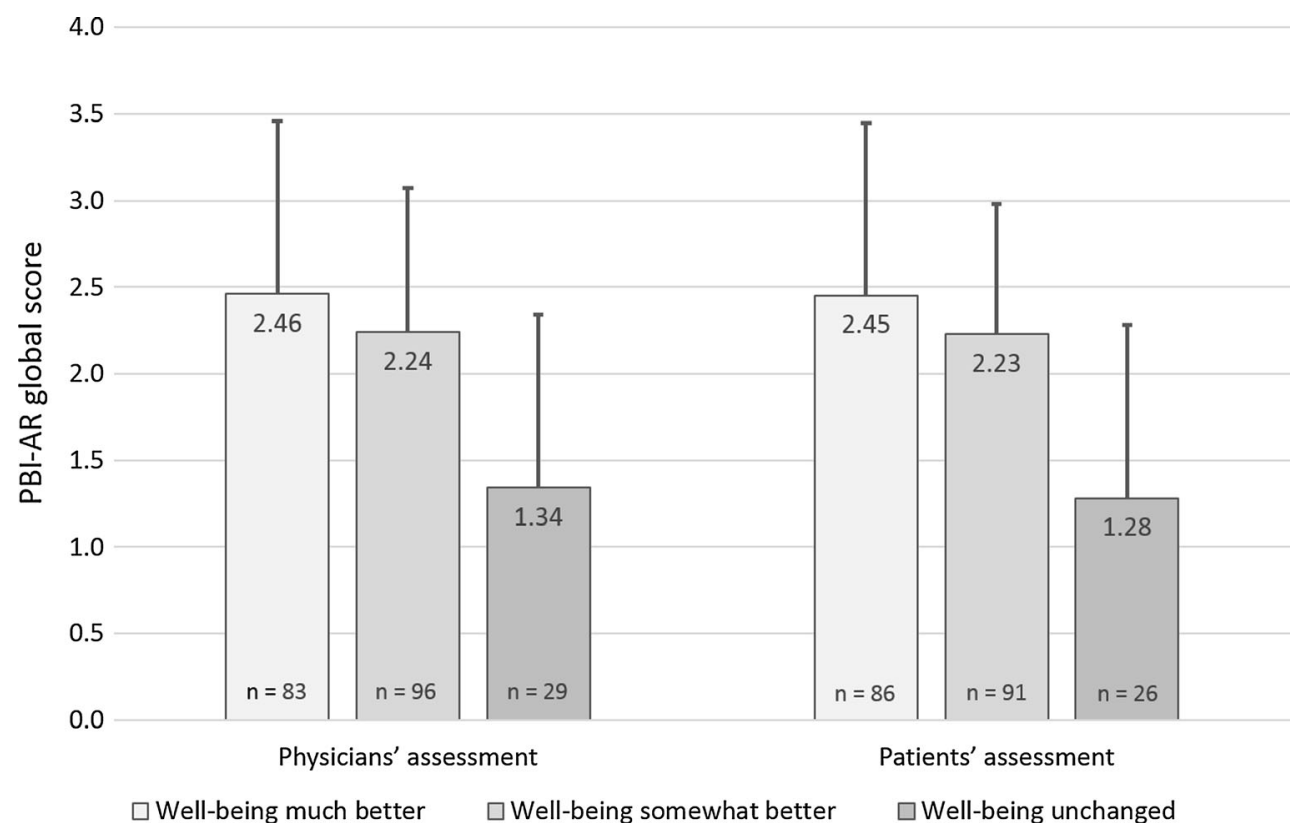

Fig. 2 PBI-AR global score (mean and SD) by physicians' and patients' judgement on improvement in well-being (second visit)

After weighting the reported benefits itemwise by the patients' individual treatment needs, a vast majority of patients (81\%) showed an at least clinically minimum relevant benefit (PBI $\geq 1$ ), and the average PBI was 2.19. This indicates that most patients who were treated with birch pollen SLIT during the observation phase of this study perceived the treatment as at least partially successful in achieving their selfdefined treatment goals, in particular with regard to the subscales "physical symptoms" and "treatment burden". Consequently, the main advantages of birch pollen SLIT treatment from the patients' perspective were shown to be an improvement of physical symptoms and a low burden of treatment.

As the severity of AR and the combination of $\mathrm{AR}$ and asthma are known to increase the overall burden of the disease and the impact on the patients $[17,18]$, and concomitant allergies may reinforce the burden even further, patient benefit was assessed in different subgroups of patients. Regardless of the clinical profile, patients benefited from treatment. Similar mean PBI-AR global scores were obtained in mono- and polyallergic patients and in patients with mild versus severe symptoms. Patients with asthma reported a patient-relevant benefit; however, this benefit was lower than in patients without asthma. In patients with persistent allergic rhinitis, benefit was higher only with regard to physical symptoms as compared to patients with intermittent allergic rhinitis. The reason for the lower response in these groups could be a higher disease burden. As goal achievement was rated by the patients themselves, patients from these subgroups may have been more hesitant to give a very good benefit assessment due to higher expectations on treatment.

While the results allow for the conclusion that patients regard the birch pollen SLIT treatment as beneficial, this non-controlled observational study has some limitations.

Effects due to other factors such as changes in birch pollen load cannot be controlled for in this kind of setting. However, according to data from the German Pollen Information Service [19], pollen load in Germany in 2013 was markedly higher than in 2012, which supports the hypothesis that the patient-reported symptom improvement from 2012 to 2013 cannot be attributed to a reduced pollen load. In addition, this study aimed to assess treatment benefit of 
Table 5 Comparison of PBI-AR global score indicating patient-relevant benefit from birch pollen sublingual immunotherapy (SLIT) between patient subgroups ( $t$-test for independent groups)

\begin{tabular}{|c|c|c|c|c|c|}
\hline PBI-AR global score & $n$ & $\begin{array}{l}\text { Mean } \\
(\mathrm{SD})\end{array}$ & $\begin{array}{l}\text { Difference between } \\
\text { means }\end{array}$ & $\begin{array}{l}95 \% \text { CI of difference (lower } \\
\text { level to upper level) }\end{array}$ & $p$ \\
\hline Male patients & 92 & $2.25(1.03)$ & 0.12 & -0.17 to 0.40 & 0.568 \\
\hline Female patients & 120 & $2.14(1.05)$ & & & \\
\hline Polyallergic patients & 127 & $2.18(1.07)$ & -0.01 & -0.29 to 0.28 & 0.954 \\
\hline Monoallergic patients & 85 & $2.19(1.01)$ & & & \\
\hline Mild rhinoconjunctivitis & 39 & $2.25(1.05)$ & 0.07 & -0.030 to 0.45 & 0.694 \\
\hline Severe rhinoconjunctivitis & 173 & $2.17(1.04)$ & & & \\
\hline Non-asthmatic patients & 160 & $2.37(0.91)$ & 0.75 & 0.38 to 1.11 & $<0.001$ \\
\hline Asthmatic patients & 52 & $1.62(1.21)$ & & & \\
\hline $\begin{array}{l}\text { Intermittent } \\
\text { rhinoconjunctivitis }\end{array}$ & 65 & $2.35(0.96)$ & 0.25 & -0.04 to 0.54 & 0.094 \\
\hline $\begin{array}{l}\text { Persistent } \\
\text { rhinoconjunctivitis }\end{array}$ & 146 & $2.10(1.07)$ & & & \\
\hline
\end{tabular}

CI confidence interval

birch pollen SLIT from the patients' perspective, which implies that all needs and benefits data represent the subjective view of the participants. Patients may understand items on need and benefits in different ways, and the retrospective benefit judgement may be subject to recall bias [20].

PBI data from 35 participants (10.7\% of 326$)$ were excluded from analysis because data were collected at the wrong time, possibly because patients' appointments were re-scheduled and/ or physicians and/or practice staff misremembered the intended time points for assessment. As this was a non-interventional study, observing treatment in routine medical practice, no study site monitoring was conducted and deviations from the planned assessments were to be expected.

Additional analyses-i.e. all analyses except for the evaluation of the PBI-AR global scoreshould be interpreted with caution, as in these explorative analyses significance values were not adjusted for multiple testing.

AIT being a long-term treatment, the recommended treatment duration is at least
3 years [8]. While this study has demonstrated patient-reported benefit of birch pollen SLIT after one birch pollen season on treatment, further investigation should be conducted to evaluate sustained or long-term benefit over more years of treatment, as indicated by existing clinical data: a clinical double-blind, placebo-controlled trial with the birch pollen SLIT extracts used in this study showed a sustained clinical efficacy after two seasons of treatment [15]. Potentially, an increase in patient benefit can be expected during the course of SLIT treatment.

\section{CONCLUSION}

Patients with AR reported considerable patientrelevant treatment benefit from SLIT with a birch pollen extract after one season of treatment, mainly due to a reduction of physical symptoms and treatment burden. This holds for different patient groups, including both polyand monoallergic patients and patients with mild and severe rhinoconjunctivitis. 


\section{ACKNOWLEDGEMENTS}

The authors thank the participants of the study. We also thank the Scientific Communication Team of the IVDP, in particular Sara Tiedemann and Mario Gehoff, for copy editing.

Funding. This study was supported by a research grant from Stallergenes $\mathrm{GmbH}$, including the Rapid Service Fee and Open Access Fee.

Authorship. All named authors meet the International Committee of Medical Journal Editors (ICMJE) criteria for authorship for this article, take responsibility for the integrity of the work as a whole, and have given their approval for this version to be published.

Disclosures. Christine Blome, Christopher Neht, Julia Kisch and Nora Kressel declare that they have no conflict of interest. Meike Hadler is an employee of Stallergenes GmbH. Efstrathios Karagiannis is the Director of Global Medical Affairs at Stallergenes Greer. Matthias Augustin has received a research grant for this study from Stallergenes $\mathrm{GmbH}$.

Compliance with Ethics Guidelines. The study protocol was approved by the Freiburg Ethics Commission International. Patients gave written informed consent and the study conformed with the Helsinki Declaration of 1964, as revised in 2013, concerning human rights.

Data Availability. The datasets analyzed during the current study are available from the corresponding author on reasonable request.

Open Access. This article is licensed under a Creative Commons Attribution-NonCommercial 4.0 International License, which permits any non-commercial use, sharing, adaptation, distribution and reproduction in any medium or format, as long as you give appropriate credit to the original author(s) and the source, provide a link to the Creative Commons licence, and indicate if changes were made. The images or other third party material in this article are included in the article's Creative Commons licence, unless indicated otherwise in a credit line to the material. If material is not included in the article's Creative Commons licence and your intended use is not permitted by statutory regulation or exceeds the permitted use, you will need to obtain permission directly from the copyright holder. To view a copy of this licence, visit http://creativecommons.org/licenses/bync/4.0/.

\section{REFERENCES}

1. Greiner AN, Hellings PW, Rotiroti G, Scadding GK. Allergic rhinitis. Lancet. 2011;378(9809):2112-22.

2. Bauchau V, Durham SR. Prevalence and rate of diagnosis of allergic rhinitis in Europe. Eur Respir J. 2004;24:758-64.

3. Dahl R, Andersen PS, Chivato T, et al. National prevalence of respiratory allergic disorders. Respir Med. 2004;98:398-403.

4. Warner JO, Kaliner MA, Crisci CD, et al. Allergy practice worldwide: a report by the World Allergy Organization Specialty and Training Council. Int Arch Allergy Immunol. 2006;139:166-74.

5. Meltzer EO. Allergic rhinitis: burden of illness, quality of life, comorbidities, and control. Immunol Allergy Clin North Am. 2016;36(2):235-48.

6. Canonica GW, Bousquet J, Mullol J, Scadding GK, Virchow JC. A survey of the burden of allergic rhinitis in Europe. Allergy. 2007;62(Suppl 85): $17-25$.

7. Brożek JL, Bousquet J, Agache I, et al. Allergic rhinitis and its impact on asthma (ARIA) guidelines2016 revision. J Allergy Clin Immunol. 2017;140(4): 950-8.

8. Roberts G, Pfaar O, Akdis CA, et al. EAACI guidelines on allergen immunotherapy: allergic rhinoconjunctivitis. Allergy. 2018;73:765-98.

9. Halken S, Larenas-Linnemann D, Roberts G, et al. EAACI guidelines on allergen immunotherapy: prevention of allergy. Pediatr Allergy Immunol. 2017;28:728-45.

10. Pfaar O, Bachert C, Bufe A, et al. Guideline on allergen-specific immunotherapy in IgE-mediated allergic diseases. Allergo J Int. 2014;23:28-65. 
11. Franzke N, Schäfer I, Jost K, et al. A new instrument for the assessment of patient-defined benefit in the treatment of allergic rhinitis. Allergy. 2011;66(5): 665-70.

12. Eton DT, Ridgeway JL, Egginton JS, et al. Finalizing a measurement framework for the burden of treatment in complex patients with chronic conditions. Patient Relat Outcome Meas. 2015;27(6):117-26.

13. Biedermann T, Winther L, Till SJ, Panzner P, Knulst A, Valovirta E. Birch pollen allergy in Europe. Allergy. 2019;74(7):1237-48.

14. Khinchi MS, Poulsen LK, Carat F, Andre C, Hansen $\mathrm{AB}$, Malling HJ. Clinical efficacy of sublingual and subcutaneous birch pollen allergen-specific immunotherapy: a randomized, placebo-controlled, double-blind, double-dummy study. Allergy. 2004;59:45-53.

15. Worm M, Rak S, de Blay F, et al. Sustained efficacy and safety of a 300 IR daily dose of a sublingual solution of birch pollen allergen extract in adults with allergic rhinoconjunctivitis: results of a double-blind, placebo-controlled study. Clin Transl Allergy. 2014;4:7.
16. Augustin M, Radtke MA, Zschocke I, et al. The patient benefit index: a novel approach in patientdefined outcomes measurement for skin diseases. Arch Dermatol Res. 2009;301(8):561-71.

17. Bousquet J, Khaltaev N, Cruz AA, et al. Allergic Rhinitis and its Impact on Asthma (ARIA) 2008 update (in collaboration with the World Health Organization, GA (2) LEN and AllerGen). Allergy. 2008;63(Suppl 86):8-160.

18. Price D, Scadding G, Ryan D, et al. The hidden burden of adult allergic rhinitis: UK healthcare resource utilisation survey. Clin Transl Allergy. 2015;5:39.

19. Stiftung Deutscher Polleninformationsdienst. Literatur und Vorträge-Studien, Analysen und Veröffentlichungen. http://www.pollenstiftung.de/ symposien-literatur/studienanalysen/. Accessed 13 Feb 2020.

20. Blome C, Augustin M. Measuring change in quality of life: bias in prospective and retrospective evaluation. Value Health. 2015;18(1):110-5. 